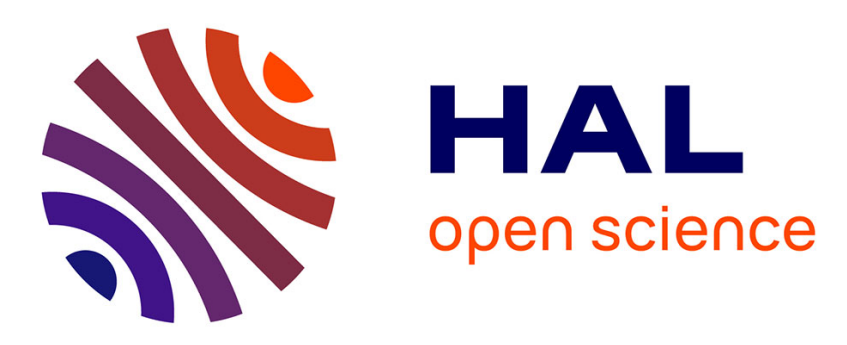

\title{
Cervical HI-RTE elastography and pregnancy outcome: a prospective study
}

Laura Sabiani, Jean-Baptiste Haumonte, Anderson Loundou, Anne-Sophie Caro, Julie Brunet, Jean-Francois Cocallemen, Claude d'Ercole, Florence Bretelle

\section{To cite this version:}

Laura Sabiani, Jean-Baptiste Haumonte, Anderson Loundou, Anne-Sophie Caro, Julie Brunet, et al.. Cervical HI-RTE elastography and pregnancy outcome: a prospective study. European Journal of Obstetrics \& Gynecology and Reproductive Biology, 2015, 186, pp.80-84. 10.1016/j.ejogrb.2015.01.016 . hal-02914208

\section{HAL Id: hal-02914208 \\ https://hal.science/hal-02914208}

Submitted on 25 May 2021

HAL is a multi-disciplinary open access archive for the deposit and dissemination of scientific research documents, whether they are published or not. The documents may come from teaching and research institutions in France or abroad, or from public or private research centers.
L'archive ouverte pluridisciplinaire HAL, est destinée au dépôt et à la diffusion de documents scientifiques de niveau recherche, publiés ou non, émanant des établissements d'enseignement et de recherche français ou étrangers, des laboratoires publics ou privés. 


\title{
Cervical HI-RTE elastography and pregnancy outcome: a prospective study
}

\author{
Laura Sabiani $^{\mathrm{a}, \mathrm{e}}$, Jean-Baptiste Haumonte ${ }^{\mathrm{a}, \mathrm{e}}$, Anderson Loundou ${ }^{\mathrm{b}, \mathrm{e}}$, Anne-Sophie Caro ${ }^{\mathrm{c}, \mathrm{e}}$, \\ Julie Brunet $^{\mathrm{d}, \mathrm{e}}$, Jean-Francois Cocallemen ${ }^{\mathrm{a}, \mathrm{e}}$, Claude D’ercole $^{\mathrm{a}, \mathrm{b}, \mathrm{e}}$, Florence Bretelle $^{\mathrm{a}, \mathrm{d}, \mathrm{e}, *}$ \\ a Department of Gynaecology and Obstetrics, Assistance Publique des Hôpitaux de Marseille (AP-HM), Aix Marseille Université, AMU, Gynépole Marseille, \\ Hôpital Nord, Chemin des Bourrely, 13915 Cedex 20 Marseille, France \\ ${ }^{\mathrm{b}}$ Medical Evaluation, Department of Public Health, Assistance Publique-Hôpitaux de Marseille, AMU, Aix-Marseille Université, Marseille, France

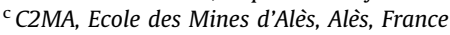 \\ d CIC 1409, Assistance Publique des Hôpitaux de Marseille (AP-HM), Aix Marseille Université, AMU, Hôpital de la Conception, 147 bd Baille, 13005 Marseille, \\ France \\ e Aix-Marseille Université, Unité de Recherche sur les Maladies Infectieuses Tropicales et Emergentes, UM63, CNRS 7278, IRD 198, Inserm 1095 Marseille, \\ France
}

\section{A B S T R A C T}

Objective: To study cervix elastography measurement and its relation with pregnancy outcome. Design: A two year prospective longitudinal study evaluated cervical elasticity by HI-RTE (Hitachi realtime tissue elastography) imaging during three trimesters of pregnancy.

The main outcome measure was elastography index the cervical elastogram color-coded.

Results: Three hundred eighty seven measurements were realized among 72 pregnant women prospectively enrolled. In the first trimester, the elasticity index was significantly lower in women who subsequently had unfavorable outcome than in women who delivered at term (respectively, EI $=0.51$ $( \pm 0.04)$ and $0.59( \pm 0.02) ; P=0.037)$. The negative predictive value of posterior lip color (blue, bluegreen $=$ hard cervix) was high NPV $=83.895 \% \mathrm{CI}[68.8-92.4]$ in the first trimester $(\mathrm{SE}=64.795 \% \mathrm{CI}[41.3-$ 82.7]; $\mathrm{SP}=60.895 \% \mathrm{CI}$ [47.1-72.9]; VPP $=35.595 \% \mathrm{CI}$ [21.1-53.1]). A first-trimester elasticity index threshold value $\leq 0.38$ had a specificity of $98.0 \%$ and a NPV of $80.9 \%$ (Se $29.4 \%$, PPV $83.3 \%$ ). This index value, when combined with a cervical length less than or equal to $36 \mathrm{~mm}$, increased the risk of adverse outcome (HR 8.87 95\% CI [3.22-23.7]).

Conclusions: Cervical elastography index is associated with unfavorable obstetrical outcomes, independently of cervical length.

The study was registered in ClinicalTrials.gov under Identifier number NCT01032564.

Keywords:

Transvaginal ultrasound

Preterm birth

Elastography

Cervical length

\section{Introduction}

Preterm birth remains an important public health problem, responsible for $75 \%$ of perinatal mortality and morbidity and accounting for $7-12 \%$ of deliveries worldwide [1]. Recent literature highlights the need for development of innovative interventions to prevent preterm birth (PB) [2].

B-mode ultrasound used to measure cervical length, serves as a diagnostic and prognostic tool for assessing the risk of PB [3-6].

\footnotetext{
* Corresponding author at: Department of Gynaecology and Obstetrics, Hôpital Nord, Chemin des Bourrely, 13915 Cedex 20 Marseille, France.

Tel.: +33 491964 853; fax: +33 491964696 .

E-mail address: florence.bretelle@ap-hm.fr (F. Bretelle).
}

Nonetheless, it happens, after all, that women with a short cervix give birth at term, and inversely, women with a long cervix deliver preterm. Identification of women at risk of preterm birth in the first trimester remains a real challenge [7]. Cervix ultrasound measurement gives no information concerning the consistency of the cervix which could help to better define the risk for preterm birth.

Cervix elastography might improve the performance of ultrasound screening evaluating its consistency. Currently littleknown in obstetrics, elastography provides information about the mechanical properties of tissues and can assess cervical consistency, using real-time color coding based on 2-dimensional imaging. This technique has been developed for studying uterine fibromas and, in particular, for cancers of the thyroid, prostate, liver and breast [8-10]. In these clinical situations it is possible to 
quantify tissue strain (deformation) with an algorithm based on a method of extended combined autocorrelation. Its first obstetric use was described in 2006, and its feasibility and reproducibility for cervical assessments have been previously reported [11-18]. During labor induction no elastographic cervical modifications through all trimesters of pregnancy in relation to preterm delivery have been observed [16]. Nonetheless, these studies most often had few subjects, rarely detailed their measurement methods. Finally most explored 2nd or 3rd trimester of pregnancy and mainly uncomplicated pregnancies.

The objective of this study was to explore the cervical elasticity throughout pregnancy and evaluate its potential interest as a tool for identification obstetrical unfavorable outcome in a high risk population.

\section{Methods}

This prospective, observational, pilot study was conducted in a level III maternity ward over a two-year inclusion period (20102012). Inclusion criteria were women at least 18 years old with a singleton pregnancy that provided informed consent. The exclusion criteria were: suspected ectopic pregnancy, multiple pregnancy, substantial vaginal bleeding, maternal diabetes, hypertension, the patient's refusal or inability to provide informed consent, and age younger than 18 years. The unfavorable outcome group was defined by preterm birth, need for emergency cerclage because of short cervix, premature rupture of the membranes. The following characteristics were registered for each woman: age, parity, smoking status, work status, body mass index.

Each woman underwent an ultrasound screening during the first, second and third trimesters of the pregnancy; these examinations included transvaginal ultrasound elastography measurements of the cervix.

After birth, the following additional data were collected: gestational age at birth and occurrence of obstetrical events.

\section{The technique of HI-RTE elastography}

Cervical elastographic measurements were performed on a standard 2-dimensional plane, that is, the longitudinal plane of the cervix, which includes the entire cervical canal from the internal to the external orifice. Accordingly, we measured the length of each woman's cervix each trimester, before the elastography.

The technique of elastography is used to evaluate the strain distribution in tissue in response to external compression. This strain distribution is usually related to the distribution of tissue elasticity: under low levels of compression, the tissue's mechanical response may follow Hooke's law $E=\sigma / \varepsilon$ where $E$ is Young's modulus, $\sigma$ the stress applied by the operator on a chosen plane section, and $\varepsilon$ the strain (relative elongation) of the observed section. Isotropic mechanical behavior of the tissue was assumed. Cervical elastography was measured with a HITACHI-Hi-Vision ultrasound system and a high frequency transvaginal probe (EUPV53W-5-9 MHz) (Hitachi EUB-8500, Wiesbaden, Germany). The correlation between elasticity and strain is defined as follows: the softer the tissue, the more easily it is strained. We coded colors as follows: red is soft tissue, green intermediate and blue hard (Fig. 1). Imaging thus makes it possible to measure the relative elasticity of the tissue of interest. By apposing an ellipse at the tissue site (with an area standardized at $1 \mathrm{~cm}^{2}$ ), it becomes possible to determine elasticity indices and to color code the elastogram (Fig. 1). Based on the study of the color coding, a cervix was classified as soft when the color ranged from red to green, and as hard, when the color ranged from blue to blue-green.

The real-time color coding must appear on the screen continuously. To obtain it, movements of compression/relaxation

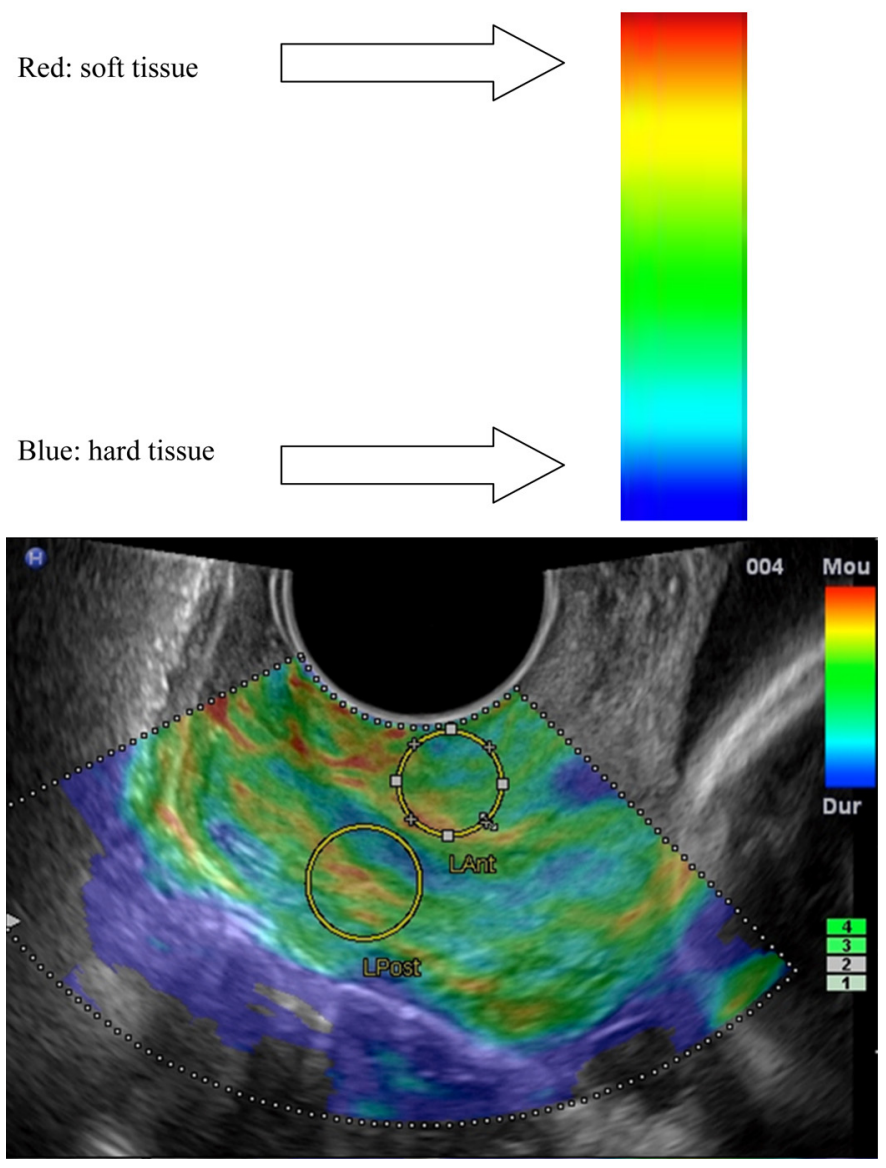

Fig. 1. Gradient of elastography color coding and elastographic image of cervix showing the measurement of its anterior and posterior lips with an ellipse and color coding of the elastogram.

must be circumscribed and as regular as possible, with regular and similar pressure represented by the green scale 3 to 4 (Fig. 1).

\section{Elasticity measures and ratios}

For each woman, the following elastography measurements (expressed as percentages) were taken: the elasticity of the anterior and posterior lips on an area of $1 \mathrm{~cm}^{2}$ at the upper, external portion; an elasticity index ratio (EI) was then calculated: $\mathrm{EI}=\mathrm{E}$ anterior $\operatorname{lip} /(\mathrm{E}$ anterior lip $+\mathrm{E}$ posterior lip). Elastography measurement inter operator variability was assessed.

The elastography measurements were realized by trained operators (mainly JBH, LS). Two independent measurements were realized during the first part of the study by two different operators. JBH did the first measurement and secondly another operator did the second measurement.

The operators were blinded to the other elastography measurements and to the final pregnancy issue but not blinded to the previous medical obstetrical history of women. The operators did not interfere in the medical treatment decisions during pregnancy and the statistical analysis was realized independently. The elastography measurement results were not given to the medical team.

\section{Statistical analysis}

We used PASW STATISTICS software Version 17 (SPSS Inc., Chicago, IL, USA). A binomial proportion confidence interval was calculated with the Wilson score and a Kaplan-Meier curve used to evaluate the survival function and univariate Cox model to 
estimate Hazard ratio (HR) with their 95\% Confidence interval. The receiver operating characteristic (ROC) curve was used to find optimal cut-off point value for cervical length and EI. A two-sided P value of less than 0.05 was considered statistically significant. The variability of the mean difference between matched pairs of IE was performed using paired student $t$ test to assess inter operator variability.

Each woman received clear information about the study modalities and the anonymization of the data. Their oral and written consents were collected and recorded, in compliance with the protocol approved by the relevant Institutional Review Board (Committee for the protection of persons participating in biomedical research, on November 4th 2009 CPP Marseille V (number 09 045), ELASTOGRAPHIE AORC 2009, 2009-A00814-53).

Power calculation. Cervical measurements can detect $40 \%$ of the women who will give birth prematurely. Our target was to screen $60 \%$ of these women a total of 50 women was necessary to obtain a statistical power of $80 \%$.

Our study was a clinical research project funded by the Marseille public hospital system (AP-HM) and was registered in ClinicalTrials.gov under Identifier number NCT01032564.

\section{Results}

From March 2010 through March 2012, the study prospectively included 72 women, whose mean age was 31 years (Table 1). Table 1 summarizes the characteristics of pregnancy population, $25 \%$ of women had an unfavorable outcome.

Inter operator variability was assessed for elastography measurement. Two EI measurements were realized for 57 women (79.1\%) and show no significant difference (mean difference $=-0.013 ; \quad P=0.825$ ). Three hundred eighty seven measurements were realized in 72 patients with two different operators measurements at each trimester of pregnancy.

\section{Cervical measurements}

Cervical length was significantly shorter at all three ultrasounds in the group of women with an unfavorable outcome compared with women with term birth $(P<0.05)$ (Table 2$)$. Cervical length less than or equal to $36 \mathrm{~mm}$ in the first quarter multiplied the risk of adverse outcome by $6.36(\mathrm{HR}=6.36,95 \% \mathrm{CI}(2.39$ to 16.92$)$ Se $38.9 \%$, Sp 94\%, PPV 70\%, and NPV 81.7\%).

Table 1

Clinical population characteristics and pregnancy issue.

\begin{tabular}{ll}
\hline Clinical data & $(n=72)$ \\
\hline Age (years) $( \pm$ SE) & $31.45( \pm 0.73)$ \\
Parity $\geq 1$ & $46(63)$ \\
Smoking & $12(16)$ \\
BMI $25-29 \mathrm{~kg} / \mathrm{m}^{2}$ & $21(29)$ \\
BMI $>30 \mathrm{~kg} / \mathrm{m}^{2}$ & $14(19.4)$ \\
Unfavorable outcome & $20(27.7)$ \\
Preterm birth & $9(12.5)$ \\
PROM & $6(8.3)$ \\
Emergency cerclage & $5(6.9)$ \\
\hline
\end{tabular}

BMI: body mass index, unfavorable outcome including preterm birth, premature rupture of membranes(PROM), need for emergency cerclage because of short cervix. SE: standard error of the mean. Except as specifically specified, all values as expressed as $n(\%)$.

\section{Cervical elastography}

During the first trimester, the EI value was significantly lower for women with an unfavorable outcome, compared with those who gave birth at term ( 0.51 vs $0.59 ; P=0.037)$ (Table 2$)$. A threshold value of EI less than or equal to 0.38 yields had a specificity of $98 \%$ (95\% CI [89.9-99.7]) and a NPV of $81 \%$ (95\% CI [69.6-88.8]) (SE 29.4\% 95\% CI [13.3-53.1], PPV 83.3\%, 95\% CI [43.797.0]). The color coding of the posterior lip had a strong negative predictive value, with a strong probability of not adverse outcome when the cervix was hard (blue): the NPV was 80\%, 95\% CI [58.491.9] during the first trimester. $\mathrm{SE}=77.895 \% \mathrm{CI}$ [54.8-91.0]; $\mathrm{SP}=31.495 \% \mathrm{CI}$ [20.3-45.0], PPV = 28.6 95\% CI [17.8-42.4].

Analysis of cervical EI and color showed no significant differences among the 2nd and 3rd trimester (Table 2).

\section{Association with cervical measurements and cervical elastography}

Finally we assess the value of EI in association with a cervical length during the first trimester, in particular among women with a long cervix. There was no correlation between elasticity ratios and cervical length. In the first trimester, the combination of an EI value less than or equal to 0.38 and a cervical length less than or equal to $36 \mathrm{~mm}$, increased the risk of an adverse outcome by 8.87 $(\mathrm{HR}=8.87 ; 95 \% \mathrm{CI}[3.22-23.71]$, SE 55.6\% 95\% CI [31.3-77.6], SP 92.3\% 95\% CI [80.6-97.5], PPV 71.4\% 95\% CI [42.0-90.4], NPV 85.7\% 95\% CI [73.2-93.2]) (Fig. 2).

\section{Comment}

This prospective study evaluating cervical elastography among pregnancy shows that it can, at the first trimester, made it possible to early identify women at risk of unfavorable outcome and this independently of cervical length. Our data are consistent with clinical observation from digital cervical examination; softness of a cervix at term is considered as favorable to induction of labor at term (as part of the Bishop score), and in the same way during pregnancy a risk factor for PB. Even if still controversial, recently several teams proved the worth of cervical length in the first trimester, including measuring the isthmus length $[7,18]$. Our results confirm this, and show in addition that an $\mathrm{EI} \leq 0.38$ on the first trimester ultrasound might enhance early screening of women at risk of unfavorable outcome.

The main strengths of this study are the serial measurements at each trimester during pregnancy and the exploration of the first trimester cervix elastography. To date no study reported the interest of elastography so early in pregnancy. Identification of women at risk remains a challenge in order to find new clues to prevent PB.

Our study has limitations related to the elastography technique and the study design. The dimension and location of the area of interest play a major role in the strain values obtained, independently of the force applied [19]. The precise site of the ellipse on the cervix, relative to the probe, must be taken into account, because the tissue near the probe deforms differently [19]. The coefficient of strain is thus higher on the anterior lips, closer to the probe, than on the posterior lip. To limit this variation, we have placed our ellipse on the superior, external portion of the cervix, a site chosen by earlier studies [15]. Moreover, the structure of the cervix is very heterogeneous, composed as it is of a microstructure with layers of collagen, associated with cystic areas, blood vessels, and in the centre, the endocervical canal. This heterogeneity can affect the speed and the orientation of deformation and thus produce varying results. Another aspect of cervical structural complexity that also affects the elastography 
Table 2

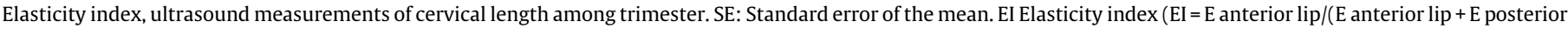
lip).

\begin{tabular}{|c|c|c|c|c|}
\hline & & Unfavorable outcome $(n=20)$ & At term $(n=52)$ & $P$ \\
\hline \multirow{3}{*}{ E anterior lip $( \pm \mathrm{SE})$} & 1 st $\mathrm{T}$ & $0.53( \pm 0.06)$ & $0.54( \pm 0.04)$ & 0.879 \\
\hline & 2nd $\mathrm{T}$ & $0.80( \pm 0.10)$ & $0.79( \pm 0.04)$ & 0.881 \\
\hline & $3 r d \mathrm{~T}$ & $0.52( \pm 0.05)$ & $0.77( \pm 0.05)$ & 0.002 \\
\hline \multirow[t]{3}{*}{ E posterior lip $( \pm \mathrm{SE})$} & 1 st $\mathrm{T}$ & $0.47( \pm 0.07)$ & $0.37( \pm 0.03)$ & 0.119 \\
\hline & 2nd $\mathrm{T}$ & $0.48( \pm 0.08)$ & $0.42( \pm 0.03)$ & 0.433 \\
\hline & $3 r d \mathrm{~T}$ & $0.51( \pm 0.11)$ & $0.49( \pm 0.03)$ & 0.827 \\
\hline \multirow[t]{3}{*}{$\mathrm{EI}( \pm \mathrm{SE})$} & 1 st $\mathrm{T}$ & $0.51( \pm 0.04)$ & $0.59( \pm 0.01)$ & 0.037 \\
\hline & 2nd $\mathrm{T}$ & $0.62( \pm 0.04)$ & $0.65( \pm 0.02)$ & 0.59 \\
\hline & $3 r d \mathrm{~T}$ & $0.54( \pm 0.06)$ & $0.61( \pm 0.02)$ & 0.257 \\
\hline \multirow[t]{3}{*}{ Cervical length $(\mathrm{mm})( \pm \mathrm{SE})$} & 1 st $\mathrm{T}$ & $38.39( \pm 1.8)$ & $47.85( \pm 1.13)$ & 0.001 \\
\hline & 2nd $\mathrm{T}$ & $34.63( \pm 5.02)$ & $46.39( \pm 1.67)$ & 0.007 \\
\hline & $3 r d T$ & $23.62( \pm 5.50)$ & $39.47( \pm 1.38)$ & 0.01 \\
\hline
\end{tabular}

measurements is its cylindrical shape. Nonetheless, despite these limitations, Fruscalzo et al., has shown that these measurements are reliable, especially for term pregnancies [17]. In our study, the color of the cervical posterior lip was more valuable than anterior's. This has been recently discussed and some authors found inversely to our finding that elasticity of cervix was linked with its length [20-22]. No clear explanation is available to date but it's admitted that elastography measurement presents variability in relation with the pressure applied on the cervix. The methods of measurement are different among studies, for example Fuchs et al. do not use a ratio but elastography measurements of an interest region set on the anterior and the posterior cervical lip [21]. Another explanation concerns the gestational age at measure. The results can be considerably different in comparison with 2nd or third trimester of pregnancy because of cervical consistency and the apply pressure because the orientation of cervix can be modify among trimester.

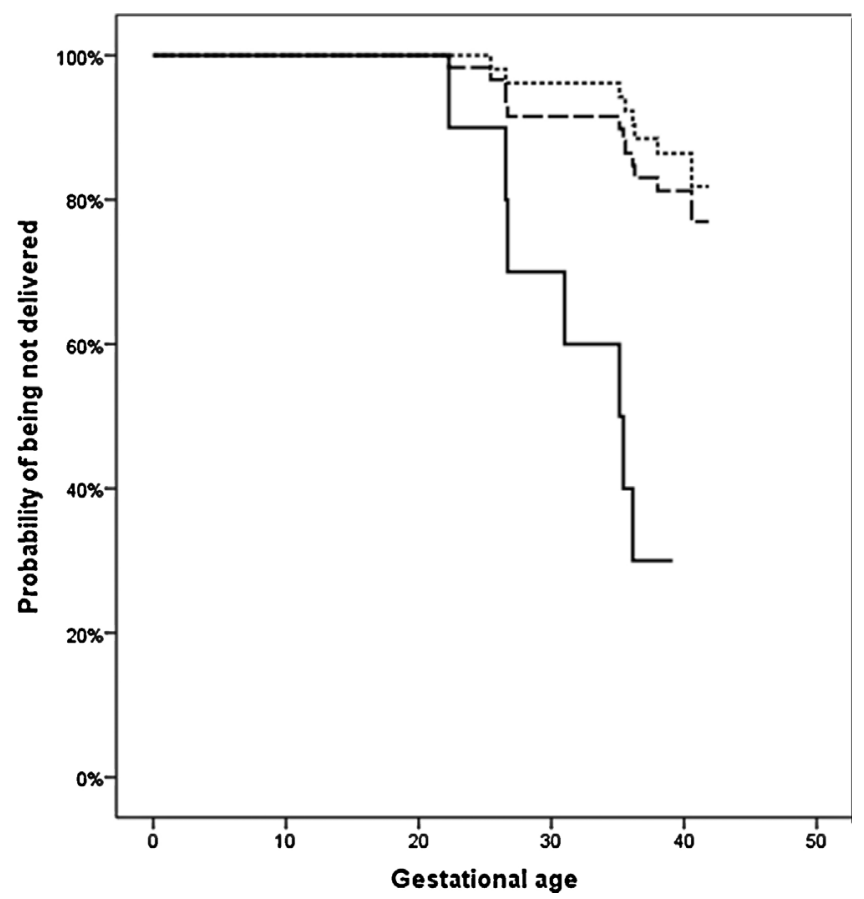

Fig. 2. Proportion of women undelivered according to gestational age for: cervical length measurement $<36 \mathrm{~mm}$ (continuous black line ---), an elasticity index $\leq 0.38$ and cervical length $>36 \mathrm{~mm}$ (discontinuous line - - -) or an elasticity index $\leq 0.38(---)$.
Another issue is how to interpret the EI value. Relying on the reasoning established for other tissues. In the breast in particular, a ratio that compares healthy to unhealthy tissue has been propose. In other tissue types, a low EI indicates fairly hard tissue and a high EI ratio soft tissue. It is difficult to extrapolate this interpretation to the cervix, since there is no reference tissue. Our results have enabled us to conclude that a low EI could play a role in the firsttrimester prediction of $\mathrm{PB}$, but do not justify an affirmation that a low value is equivalent to a soft cervix.

Our study took place in a high risk population. Our result could be further studied in a multicenter study and in a population more representative before being routinely used. The measurement of the EI is thought not to be related to the pressure applied by the operator since it involved a ratio. Nevertheless it is expected that the value of the applied pressure should not exceed a critical value that would invalidate the assumption of linear elasticity; on the other hand, the color coding is related to pressure and might have influenced the results.

Several studies have already demonstrated reproducibility of elastography measurements $[17,19]$. Nonetheless, standardization of the settings for the elastography devices is necessary, especially for the contact and velocity pressure. Under a low level of deformation, the mechanical behavior of tissue can be considered as elastic; in some cases the elastic modulus is time and temperature dependent [21]. Moreover some authors have also detected a non-linearity in mechanical behavior that calls into question the validity of the elastic assumption [22]. Our protocol enables an assessment of elasticity but in the future it might be necessary to evaluate the dependence of EI on time and pressure to make the protocol fully non-operator dependent and to check the elasticity assumption (by monitoring the stress and strain).

An ultrasound transducer-type automated system, mounted in a mechanical piston that regulates the compression, is under evaluation [23]. Currently, it is widely used in liver disease to avoid hepatic puncture [24].

Some efforts should be made to standardize application pressure methods, shear stress methods could decrease this need, but this should also be explore.

First trimester cervical elasticity appears to be associated with obstetrical outcome. Complementary research should work on standardization of measurement methods.

\section{Disclosure}

The authors report that Hitachi lend to the Gynepole Marseille an HITACHI Hi-Vision ultrasonographer with transvaginal probe (5-9 MHz, Hybrid generation) for 6 months. 


\section{Condensation}

Cervical elastography index is associated during the first trimester to further unfavorable obstetrical outcomes, independently of cervical length.

\section{Conflict of interest statement}

Hitachi lend to the Gynepole Marseille an HITACHI Hi-Vision ultrasonographer with transvaginal probe (5-9 MHz) for 6 months.

\section{Ethics approval}

The protocol was approved by the Institutional Review Board (Committee for the protection of persons participating in biomedical research, on November 4th 2009 CPP Marseille V; number 09 045), ELASTOGRAPHIE AORC 2009, 2009-A00814-53.

\section{Funding}

Assistance publique des hôpitaux de Marseille (AP-HM) funded this research (National Public Grant). This study was registered at ClinicalTrials.gov, Identifier NCT01032564.

\section{Acknowledgements}

Marie-Alice Coullomb, Claire Tourette, Melinda Petrovick, Renaud Le Du, Aurore Aziz, Sophie Hamouda, Emannuelle Assouline and Christelle Arbola for cervical length and elastography measurement.

\section{References}

[1] Blondel B, Lelong N, Kermarrec M, Goffinet F. Coordination nationale des Enquêtes Nationales Périnatales Trends in perinatal health in France between 1995 and 2010: results from the National Perinatal Surveys. J Gynecol Obstet Biol Reprod 2012;41:151-66.

[2] Chang $\mathrm{HH}$, Larson J, Blencowe $\mathrm{H}$, et al. Born too soon preterm prevention analysis group preventing preterm births: analysis of trends and potential reductions with interventions in 39 countries with very high human development index. Lancet 2013:381:223-34.

[3] Conde-Agudelo A, Papageorghiou AT, Kennedy SH, Villar J. Novel biomarkers for the prediction of the spontaneous preterm birth phenotype: a systematic review and meta-analysis. BJOG 2011;118:1042-54.

[4] Gomez R, Galasso M, Romero R, et al. Ultrasonographic examination of the uterine cervix is better than cervical digital examination as a predictor of the likelihood of premature delivery in patients with preterm labor and intact membranes. Am J Obstet Gynecol 1994;171:956-64.

[5] Iams JD, Goldenberg RL, Meis PJ, et al. McNellis The length of the cervix and the risk of spontaneous premature delivery National Institute of Child Health and
Human Development Maternal Fetal Medicine Unit Network. N Engl J Med 1996:334:567-72

[6] Conde-Agudelo A, Romero R, Nicolaides K, et al. Vaginal progesterone vs. cervical cerclage for the prevention of preterm birth in women with a sonographic short cervix, previous preterm birth, and singleton gestation: a systematic review and indirect comparison metaanalysis. Am J Obstet Gynecol 2013;208(42):42.e1-42.e18

[7] Sananes N, Schuller E, Gaudineau A, et al. What is predictive of preterm delivery in the first trimester: isthmus or cervical length? Prenat Diagn 2013;33:894-8

[8] Ami O, Lamazou F, Mabille M, et al. Real-time transvaginal elastosonography of uterine fibroids. Ultrasound Obstet Gynecol 2009;34:486-8.

[9] Pallwein L, Mitterberger M, Pinggera G, et al. Sonoelastography of the prostate: comparison with systematic biopsy findings in 492 patients. Eur J Radiol 2008;65:304-10.

[10] Rago T, Santini F, Scutari M, Pinchera A, Vitti P. Elastography: new developments in ultrasound for predicting malignancy in thyroid nodules. J Clin Endocrinol Metab 2007;92:2917-22.

[11] Thomas A. Imaging of the cervix using sonoelastography. Ultrasound Obstet Gynecol 2006;28:356-7.

[12] Feltovich H, Hall TJ. Quantitative imaging of the cervix: setting the bar Ultrasound Obstet Gynecol 2013;41:121-8.

[13] Fruscalzo A, Schmitz R, Klockenbusch W, Steinhard J. Reliability of cervix elastography in the late first and second trimester of pregnancy. Ultraschall Med 2012;33:E101-7

[14] Molina FS, Gómez LF, Florido J, Padilla MC, Nicolaides KH. Quantification of cervical elastography: a reproducibility study. Ultrasound Obstet Gynecol 2012;39:685-9

[15] Swiatkowska-Freund M, Preis K. Elastography of the uterine cervix: implications for success of induction of labor. Ultrasound Obstet Gynecol 2011;38:52-6.

[16] Fruscalzo A, Steinhard J, Londero AP, et al. Reliability of quantitative elastography of the uterine cervix in at-term pregnancies. J Perinat Med 2013;41:1-7.

[17] Hernandez-Andrade E, Hassan SS, Ahn H, et al. Evaluation of cervical stiffness during pregnancy using semiquantitative ultrasound elastography. Ultrasound Obstet Gynecol 2013:41:152-61.

[18] Souka AP, Papastefanou I, Michalitsi V, et al. Cervical length changes from the first to second trimester of pregnancy, and prediction of preterm birth by first-trimester sonographic cervical measurement. J Ultrasound Med 2011:30:997-1002.

[19] Al Naimi A, Fittschen M, Bahlmann F. Measuring cervical strain with tissue Doppler imaging depending on the shape and placement of the region of interest and its correlation with cervical consistency index. Eur J Obstet Gynecol Reprod Biol 2014;179:246-50.

[20] Hee L, Sandager P, Petersen O, Uldbjerg N. Quantitative sonoelastography of the uterine cervix by interposition of a synthetic reference material. Acta Obstet Gynecol Scand 2013;92:1244-9.

[21] Fuchs T, Woyton R, Pomorski M, et al. Sonoelastography of the uterine cervix as a new diagnostic tool of cervical assessment in pregnant women-preliminary report. Ginekol Pol 2013;84:12-6.

[22] Kruse SA, Smith JA, Lawrence AJ, et al. Tissue characterization using magnetic resonance elastography: preliminary results. Phys Med Biol 2000;45:157990.

[23] Farshad M, Barbezat M, Flueler P, Schmidlin F, Graber P, Niederer P. Material characterization of the pig kidney in relation with the biomechanical analysis of renal trauma. J Biomech 1999;32:417-25.

[24] Yeh WC, Li PC, Jeng YM, et al. Elastic modulus measurements of human liver and correlation with pathology. Ultrasound Med Biol 2002;28:467-74. 